\title{
Academic Performance of Students: the Effect of Class Room Level Factors and Private Tutoring
}

\author{
B.W.R. Damayanthi" \\ Department of Economics, University of Sri Jayewardenepura, Sri Lanka \\ *Corresponding author: bwrdam@sp.ac.lk
}

\begin{abstract}
Increased participation in private tutoring intended towards the high academic performance has been perceived enormously worldwide. However, to date literature is indecisive about the effect of private tutoring on students' academic performance. This study directed to observe the impact of private tutoring on students' academic performance in Sri Lanka. Data was collected from a stratified systematic random sample of 600 children were in Year $7-11$ and their parents through a questionnaire survey. It was found that private tutoring has positive effect on students' academic performance while net impact of private tutoring on student's academic performance is reduced in magnitude when parental education, economic status and especially the effect self leaning hours is concerned. Hence, the study concludes that rather than focusing on private tutoring, efforts to improve self learning strategies that enhance socio-cultural connectedness and human focus can lead to achieve wider goals of education.
\end{abstract}

Keywords: private tutoring, student performance, Sri Lanka

Cite This Article: B.W.R. Damayanthi, "Academic Performance of Students: the Effect of Class Room Level Factors and Private Tutoring." American Journal of Educational Research, vol. 6, no. 3 (2018): 262-269. doi: 10.12691/education-6-3-13.

\section{Introduction}

In recent decades, Private Tutoring (PT) has become critical phenomenon throughout the world. Scholars have identified several reasons for the growing existence of PT worldwide. The deficiencies in formal education systems in developing countries such as low public education expenditure, limited access to the university education and competitive examinations to get access for further education have been identified predominant causes for the growth of PT $[1,2]$. However, PT is widespread in developed countries irrespective of the quality of formal education system $[3,4,5]$. For example, in countries like Canada, Hong Kong, Japan, Singapore, the United Kingdom and the United States of America [4,5,6] display a remarkable growth rate in PT. The volume of PT is ranging from 30 to 90 percent worldwide [2,3,7]. When observing the general features of PT it can be noted that students with higher socio-economic status tend to spent more time and money on PT than students with lower socio-economic status [8]. Moreover, as in early decades PT is not limited only to lower performing students but also for well competent students in order to improve their existing knowledge. Participating in PT has positive as well as negative socio-economic implications on students [4]. PT creates social inequality by placing more economic burden on middle and low income families. Further, it exerts an excessive pressure on children limiting their leisure activities and formal school activities. However, benefits of PT include, constructive out-of-school activities for students, and in future they might be able to move to higher economic status with the high academic achievements.

PT has gained an increasing attention within the current education system of Sri Lanka. Irrespective of the school grade, from junior secondary to senior secondary level most of the school children tend to attend private tuition classes in addition to day to day schooling. The intensity of PT is gradually increasing when students get promoted to higher school levels [7]. Students in senior secondary level (grades 12 and 13) tend to attend private tuition classes rather than attending the formal school sessions during the terms of tertiary education entrance exams. Studies revealed that PT participation is considerably high regardless of the student's grade and the parental income level. According to ADB (2017) PT is the largest component of Sri Lanka's household education budget, with a recorded share of 45 percent. According to De Silva [9] 80 percent of Year 6 students attended some form of private tuition classes while this proportion was 75percent for Year 11 students in 1990. As in Aturupane, Glewwe, and Wisniewski, [10], about 74 percent of grade four students attend PT and according to Cole this percentage is 35 [11].

Having said above, several causes of PT can be identified in Sri Lankan context. Firstly, inefficiencies of the formal education system due to low expenditure on education has led to growing participation in PT [10]. Consequently, large class size and thus high teacher-student ratio, unequal distribution of educational resources among schools such as library, laboratory, etc. and low number of state universities is witnessed in the education system [11,12]. More importantly, parents encourage the students to attend PT to enhance their 
children's academic performance so as to get them high achievements in competitive national level exams, which boost their chances of admitting to state universities. The popular belief in Sri Lanka context is that the admission to state universities provides better and state secured employment prospects and social rewards.

PT in Sri Lanka is widespread with a rapidly growing participation rate. Auxiliary to formal schooling parents allocate a significant portion of household budget for PT. However, it has been reported that many Sri Lankan students display weak academic performance at national level examinations. Yet effective policies are not introduced to improve their performance have not identified so far [10]. Further, whether or not private tutoring benefits children's educational outcomes is still debated in the globe $[13,14]$ while conclusions from few studies found in the local context are in dispute $[10,11]$. Given this context, quantifying the effect of private tutoring on students' academic performance would be expedient to the educationists and policy makers to form effective policies and further to overcome negative impacts of PT. Hence, this study aims at investigating the effect of PT and class room level factors on the academic performance of students who are in Year $7-11$ selecting from four districts in Sri Lanka.

Following the introduction, the rest of the paper is organized as follows. Section 2 discusses the literature pertaining to impact of private tutoring on students' academic performance and formal education system of Sri Lanka. Section 3 and 4 provides information about the data used in the study and the empirical model respectively. Analyzed results are presented and discussed in the section 5 while the last section concludes the study.

\section{Literature on Impact of Private Tutoring and the Formal Education System in Sri Lanka}

\subsection{Literature on Impact of Private Tutoring}

A very large literature has documented the effects of PT on children's educational outcomes. According to Liu [8], attending PT has significant positive impact on students' academic performance. Further, a study by Aturupane et al [10], has concluded that PT has a significantly large impact on academic performance of students. Moreover, Thongphat [15], has found that PT has significantly positive impact on Mathematics and English language. Besides, he has concluded that family background factors and educational background factors have a significant positive impact on students' Mathematics and English language scores. Unal, Ozkan, Milton, Price and Curva [16], have identified that PT has a strong positive effect on mathematics performance of the all four occupational categories of parents. Another study by Byun and Park [17], has found that students who take commercial SAT preparation courses have positive effect on SAT scores of East Asian American students. Dang [1], have examined the determinants of expenditure on private tutoring and impact of private tuition expenditure on students' performance in Vietnam. His findings suggest that private tuition expenditure is a necessity among the primary and lower secondary students of Vietnam and further the study reveals that there is a positive impact from private tuition on students' academic performance. Further, Berberoglu and Tansel [18], have also found that PT has a positive but relatively small impact on student performance than the other variables: Interest and perception of academic success, parental education, and socio cultural background [37].

A study by Kuan [19], also suggest that participation in Math cram schooling (PT) have a positive but small impact on student performance of grade nine students and influence of cram schooling on math score vary with the education level of parents, prior knowledge of Mathematics, and student's willingness in participating cram schooling. Ha and Harpham [20] have found that private tutoring does increase the reading ability although it does not have an impact on the writing and numeracy skills of the grade 8 students of Vietnam. Further, Zhang [14], has observed on the effects of private tutoring and identified it has mixed effects on mathematical, Chinese language and English language in China (also in [21]). Conversely, Cole [11], a study on the effect of private tutoring on grade 5 scholarship exam performance in Sri Lanka reveals that there is no effect of private tutoring on students' scores.

Further, self-efficacy which has been defined as an 'individual's confidence in their ability to organize and execute a given course of action to solve a problem or accomplish a task' $[22,23]$ has found as an important predictor of individual' academic achievement (Williams et al., 2017. If students are confident that they are capable in accomplishing goals, they are more likely to self regulated and persist with self leaning.

Apart from above, there are several other studies which focus on the impact of school quality on student performance. According to Chiu [24], school characteristics have a significant impact on the mathematics achievement of students controlling for country and family characteristics. Another study by Heyneman and Loxley [25], by examining data from primary schools of 29 high and low income countries has concluded that teacher's quality predominantly influence the student performance. Further, a Sri Lankan study by Silva and Banneheka [26], has identified school exercises as the most significant factor influencing student performance. The interest in mathematics and school type was identified as the next most influential factors. However, Hanushek [27] has claimed that school resources have no strong impact on student performance after controlling the factors associated with background.

\subsection{Formal Education System and Private Tutoring in Sri Lanka}

In Sri Lanka, free education is provided for all students from the primary stage to the first degree level of university. The education span is about thirteen years and students who completed all thirteen years successfully can join for universities and tertiary institutes to continue with their higher education. However, from age 5 to 16 years education is compulsory and students are provided with a range of welfare services such as, free text books, free school uniforms, midday meal for primary students at 
disadvantaged schools, free healthcare services, and subsidized transport. In Sri Lanka, At present, there are 9931 government schools and 98 recognized private schools. Among the 9931 government schools, 342 schools are governed by the Central Ministry of Education and others from the provincial council. Further, government schools are classified according to the terminal grade of the school and complexity of the courses offered by the school. Schools which offer all subject streams (namely, Science, Arts and Commerce) for GCE AL with or without primary section as type $1 \mathrm{AB}$, schools which offer Arts and Commerce subjects for GCE AL with or without primary section as type $1 \mathrm{C}$, schools which have classes up to GCE OL as type 2, and schools which terminate at grade 5 or 8 as type 3. Primary education in SL includes grades 1 to 5 . Secondary education has two stages, junior secondary education (from grade 6 to 9) and senior secondary education (from grade 10 to 13 ). Tertiary education consists of university undergraduate education, other professional education and postgraduate education. There are three public examinations conducted by the Department of Education, scholarship and placement examination at grade 5, GCE OL examination at the end of grade 11, and GCE AL examination at end of grade 13 (which is the school leaving examination and selection examination for the local universities). However, availability of free first degree level university education is limited due to the high cost involved with the tertiary education. Only $6 \%$ of the students who sit for the GCE AL examination get an opportunity to admit to the local universities. Hence, due to the high competition an excessive pressure is enforced on students, increasing the demand on PT.

\section{Materials and Methods}

\subsection{Data and Variables}

The data for this study was collected from a stratified systematic random sample of 800 students studying in grade 7 - grade 11 and also from their parents in the Colombo, Kalutara, Galle and Matara districts. Questionnaire survey was conducted in 2017 under interview method. The dependent variable is the average score of three subjects, namely Mathematics, Science and English obtained at the last term test in the year prior to the survey year. Marks were obtained from the schools of which the students attend.

Explanatory variables of the study include Individual level variables, and classroom level variables. Individual level variables related to PT are considered as follows; PT participation (as dummy assigning value 1 if participant), the private tuition expenditure incurred by the household (sum of tuition fee and all other related expenses) [17], number of private tuition classes per week, average private tutoring hours a student take per week. Except the student demography details such as gender, age, socio-economic status of family which comprise of household expenditure, father's and mother's education level and the employment status [1,17,20] were taken as the main controlling factors. Further, this study considered the number of siblings as an explanatory variable $[1,2,11,28]$ because of its spillover effects. Motivation for learning is also considered as an individual level variable which is measured through self-learning hours, while student's satisfaction on teaching-learning process was taken as student's school-wellbeing. Parents' involvement in their children's education was measured through four sub domains; parent child communication, home supervision, and school connectedness - contact and participation- [29] Principle component method base linear composites for the above dimensions were created through varimax rotation and used as predictors. Furthermore, a single parental involvement index was also created with the help of 13 questions covering above four dimensions. Cultural capital was considered as an important variable to denote the influence of home base resources for the socialization process of children. An index was created for cultural capital using 6 items in the parents' questionnaire. Teacher quality is also one of the 10 linear composites that were created using PCM. At the classroom level, teacher's perception on class size, time allocation, teacher's workload and experience were the main variables that are at level 2 .

\subsection{Econometric Framework}

The basic objective of the present study is to examine effects of individual and classroom level factors on the student's academic performance which utilizes the data at two levels having nesting structure. Linear mixed effect model is an appropriate statistical technique to analyze data not only with such a hierarchical structure but also the possibility of handling variables measured at different levels; micro, macro simultaneously [30,38,39]. Hence, a two-level linear mixed effect model was used to estimate the effects of student-level and classroom-level variables on students' performance. This model is more appealing firstly because the dependent variable is a continuous. Secondly, it takes into account both variations that is explained by the independent variables of interest - fixed effects, variation that is not explained by the independent variables of interest - random effects and occupy random terms for each level. Accordingly, the level-1 and level-2 models are as follows.

The model at student or individual level takes form as in the equation 1 ,

$$
y_{i j}=\beta_{0}+\beta_{1} x_{i j}+\varepsilon_{i j}
$$

When $y_{i j}$ is functionally depends on the multi level factors, the level-1 model takes the form as in equation 2 ,

$$
y_{i j}=\beta_{0 j}+\beta_{1} x_{i j}+\varepsilon_{i j}
$$

In this model the intercept $\beta_{0 j}$ depends on the group but the regression coefficient of $x, \beta_{1}$ is constant. In this level1 model $\beta_{0 j}$ is the average performance score. $\beta_{1}$ is the average differential in performance score associated with individual level factors across all schools. $\varepsilon_{i j}$ is the individual or the level-1 residual term.

In order to construct a two level linear mixed model, the group dependent intercept, $\beta_{0 j}$, can be expressed as a sum of a constant $\beta_{0}$ and random term $\mu_{0 \mathrm{j}}$ as in equation 3 :

$$
y_{i j}=\left(\beta_{0}+\mu_{0 j}\right)+\beta_{1} x_{i j}+\varepsilon_{i j}
$$


Denoting $\beta_{0}=\gamma_{00}$

$$
\beta_{0 j}=\gamma_{00}+\mu_{o j}
$$

Substituting this level-2, in to level-1 model in equation 2 and rearranging, $\mathrm{y}_{\mathrm{ij}}$ can be expressed as

$$
y_{i j}=\gamma_{00}+\beta_{1} x_{i j}+\left(\mu_{0 j}+\varepsilon_{i j}\right) .
$$

The model specified in the equation 5 is considered for the study predominantly in investigating the impact of private tutoring and teacher quality on students' academic performance using the facilities available in the command "mixed" in STATA 14.0.

\section{Results}

Table 1 reports the basic demography of the sample and the descriptives of the continuous variables. Accordingly, as in the general context, gender composition has been made as 40 percent males and 60 percent females. Most of the sampled students were at the age of 13 years, while mid data point is also 13 years. One the grade composition was taken, the highest representation was from grade 11 while the sample representation from grade 9 is slightly low. Average score of three main subjects i.e. mathematics, science and English, was 51 while it was 53 and 25 for PT attendees and non-attendees respectively. As shown in Table 1, as a household, on average, spend Rs. 3800 on PT including direct tuition fee and mean $\mathrm{HH}$ expenditure when extreme values are excluded was Rs. 39000. Among the socioeconomic variables, parental education recorded that the majority of the parents were above $\mathrm{O} / \mathrm{L}$ but below graduate level.

\begin{tabular}{|c|c|c|c|c|c|}
\hline & Mean & Median & PT:Yes & $\mathrm{PT}:$ No & \\
\hline Score & 51 & 50 & 53.4 & 25.2 & \\
\hline Trimmed & & & 53.8 & 24.1 & \\
\hline Stu age & 13.7 & 13 & & & \\
\hline Gender & $\%$ & & PT expenditure Rs. & & \\
\hline Male & 40.0 & & Mean & 3815.9 & \\
\hline Female & 60.0 & & Median & 2800.0 & \\
\hline Grades & $\%$ & & HHexpen & & \\
\hline 7 & 20.6 & & 5\% Trimmed Mean & 39096.6 & \\
\hline 8 & 22.4 & & Median & 35500.0 & \\
\hline 9 & 16.2 & & & & \\
\hline 10 & 16.7 & & & & \\
\hline 11 & 24.1 & & & & \\
\hline No PT classes & Weekly & & Education Yrs & Father & Mother \\
\hline 0 & 14.3 & & Primary less & 3.9 & 4.5 \\
\hline 1 & 10.0 & & 6-10 & 21.0 & 15.6 \\
\hline 2 & 15.7 & & $11-12$ & 36.9 & 45.9 \\
\hline 3 & 26.5 & & $\mathrm{~A} / \mathrm{L}$ & 30.1 & 30.6 \\
\hline 4 & 18.3 & & A / L above & 3.7 & 3.3 \\
\hline 5 & 10.9 & & & & \\
\hline 6 & 3.5 & & & & \\
\hline 7 & .4 & & & & \\
\hline 8 & .4 & & & & \\
\hline Mean & 2.8 & & & & \\
\hline
\end{tabular}

Table 1. Sample characteristics \& Descriptive statistics

Source: Author's calculations based on survey data.

\begin{tabular}{|c|c|c|c|c|}
\hline \multirow[t]{2}{*}{ Variable } & \multicolumn{4}{|c|}{ Quartile Mean } \\
\hline & Q1 & Q2 & Q3 & Q4 \\
\hline Father_eduYrs & 8.8 & 9.2 & 11.1 & 12.0 \\
\hline Shib_Ēld & 1.5 & 1.3 & 1.3 & 1.3 \\
\hline Shib_yung & 1.4 & 1.1 & 1.0 & 1.2 \\
\hline Freq_sick & 0.4 & 0.3 & 0.3 & 0.1 \\
\hline Health behavior & -0.1 & .04 & -0.1 & .02 \\
\hline Cultural capital & -0.3 & -0.3 & -0.1 & 0.3 \\
\hline Family relationship & -0.2 & -0.1 & .01 & 0.2 \\
\hline Interpersonal relationship & -0.2 & -0.1 & 0.1 & 0.2 \\
\hline Study related stress & 0.1 & 0.1 & 0.2 & 0.3 \\
\hline Parent communication & -0.2 & .05 & 0.1 & -0.1 \\
\hline Home supervision & .02 & .05 & 0.1 & 0.3 \\
\hline School satisfaction & 1.5 & 1.6 & 1.7 & 1.7 \\
\hline School parent connectedness & -0.2 & .02 & 0.2 & -0.1 \\
\hline Perceived teacher quality & 0.1 & .04 & .04 & 0.1 \\
\hline Mother emp or nt & 0.3 & 0.3 & 0.2 & 0.3 \\
\hline HH expenditure & 29726.8 & 42000.3 & 41061.1 & 46792.4 \\
\hline Total expenditure PT & 1431.6 & 2752.7 & 4072.0 & 4147.6 \\
\hline Math_fees & 556.3 & 573.5 & 633.0 & 565.6 \\
\hline Sci_fees & 473.0 & 559.8 & 679.2 & 509.6 \\
\hline Eng_fees & 492.6 & 509.8 & 590.4 & 520.5 \\
\hline No of PT classes (weekly) & 1.4 & 2.5 & 3.2 & 3.8 \\
\hline
\end{tabular}

Table 2. Unconditional results: Quartile distribution of main variables

Source: Author's calculations based on survey data. 
Table 2 depicts the unconditional results derived through descriptive statistics for quartiles of the dependent variable; mean score. Students in quartile one can be categorized as weakly performed while the students in Q4 are the best performers. As reports, father's education level measured in years was quite low in Q1 while Q4 records the highest. There can be seen between quarter variations for the number of elder siblings, younger siblings, frequent sickness and health behavior but no pattern is evidenced. Student's social and psychological wellbeing related variables: Cultural capital, Family relationship, Interpersonal relationship shows a monotonic increase from Q1 to Q4. Compared to low performers, students in Q4 were rich in cultural, family and social relationships. Further, school satisfaction was also high for Q4. In contrast, compared to lower performers in Q1 or Q2, students in Q4 were highly stressed while parent-school connectedness, parental communication as well as home supervision for them were comparatively low. Once teacher related factors or level-2 factors are concerned, perceived teacher quality was high for the middle two quartiles. Households in Q4 were quite rich spending more than Rs. 46000 per month. Quartile average of the total tuition expenditure in Q4 was Rs. 4147 which is three times greater than that of Q1. Moreover, number of tuition classes attended a week varies from 2 in Q1 to 4 in Q4 showing a clear pattern.

Table 3 presents the results from the two-level mixed effect model. Before estimating the model, the existence of nesting structure of the data and thereby the relevance of applying hierarchical mixed effect model was checked. It was found that 3.8 percent of the total variation is attributed to level-2. The value of intra class correlation coefficient is small but significant confirming the nesting data structure.

In order to assess the net impact of involvement in private tuition on student's academic performance, six successive models were estimated as reports in the Table 3.
It was taken account of student level characteristics, including family background, study and school related psychological measures, amount of time spent on homework, PT participation and class room level factors. PT participation which takes value 1 for the participants is statistically significant at conventional levels in all models albeit the effect size and the significance levels are varied. Table 3 depicts the standardized beta coefficients which give the contribution of each variable to the model measured in standard deviation units (Field, 2009, p. 239). PT is positively significant recording standardized beta values $0.271, \mathrm{p}<.001 ; 0.192, \mathrm{p}<.001 ; 0.133 \mathrm{p}<.001 ; 0.118$ $\mathrm{p}<.01 ; 0.057, \mathrm{p}<.05 ; 0.051, \mathrm{p}<.05$ for models 1 to six respectively. Once the results of full model reported in the last column was taken, Father's education and Self study hours were the most significant predictors of academic performance which estimate one standard deviation unit increase in these variables would increase the academic performance by .36 and .295 slandered deviation units respectively. Further it was found that Mother's education, Self efficacy and Family relationship are statistically significant recording $\mathrm{p}$ value less tha.01 while PT participation, home supervision, cultural capital, log of household expenditure and inter personal relations are positively contribute to the level of academic performance. As expected, frequent sickness of the student was negatively associated and hardly significant. Although the effect size was negligible, perceived teacher quality affects performance at .05 percent level of significance. It was seen that mother's employment negatively impact on the academic achievement but not a significant predictor to the model. Similarly, class room level factors (physical facilities) records positive coefficient value but records no significance in predicting student's academic performance. At the contextual level, Teacher's experience and in class practices were the significant contributors reporting coefficient values as 0.163 and .033 . As usual, teacher workload was negatively impacted on student academic performance.

Table 3. Results of hierarchical linear mixed models

\begin{tabular}{|c|c|c|c|c|c|c|}
\hline \multirow[b]{2}{*}{ Fixed effects } & \multicolumn{6}{|c|}{ Models } \\
\hline & 1 & 2 & 3 & 4 & 5 & 6 \\
\hline PT [participate $=1]$ & $0.271 * * *$ & $0.192 * * *$ & $0.133 * *$ & $0.118 * *$ & $0.057^{*}$ & $0.051 *$ \\
\hline Farther Edu Yrs & & $0.517 * * *$ & $0.423 * * *$ & $0.374 * * *$ & $0.386 * * *$ & $0.356 * * *$ \\
\hline Mother Edu Yrs & & $0.212 * * *$ & $0.153 * *$ & $0.158 * *$ & $0.121 * *$ & $0.111^{* *}$ \\
\hline Home supervision & & & $0.131 * *$ & $0.123 * *$ & $0.093 *$ & $0.093 *$ \\
\hline Cultural capital & & & & $0.148 * *$ & $0.067 *$ & $0.065^{*}$ \\
\hline Self efficacy & & & & $0.168 * *$ & $0.203 * *$ & $0.188 * *$ \\
\hline Mother employed [yes] & & & & & -0.080 & -0.070 \\
\hline Self Study Hrs & & & & & $0.297 * * *$ & $0.295 * * *$ \\
\hline Family relationship & & & & & & $0.177 * *$ \\
\hline Interpersonal/Social relation & & & & & & $0.102 *$ \\
\hline Frequently sick & & & & & & $-0.032 *$ \\
\hline Perceived teacher quality & & & & & & $0.007 *$ \\
\hline School satisfaction & & & & & & 0.022 \\
\hline Teacher work load[hrs/week] & & & & & & $-0.032 *$ \\
\hline Teacher experience & & & & & & $0.162 *$ \\
\hline Teacher satisfaction & & & & & & 0.023 \\
\hline In class practice [hrs/week] & & & & & & $0.033^{*}$ \\
\hline \multicolumn{7}{|l|}{ Auxiliary } \\
\hline PT [expenditure] & $0.419 * * *$ & $0.289 * * *$ & $0.277 * *$ & $0.260 * *$ & $0.248^{*}$ & $0.219^{*}$ \\
\hline Number of PT classes & $0.555 * * *$ & $0.418 * * *$ & $0.396 * *$ & $0.370 * *$ & $0.318^{*}$ & $0.302 *$ \\
\hline
\end{tabular}

$* * * \mathrm{p}<0.001 ; * * \mathrm{p}<0.01 ; * \mathrm{p}<0.05$ 


\section{Discussion}

From the analysis of the student-level and school-level factors influencing the student's academic performance, several findings are required to be taken into consideration. First, there is clear evidence that the academic performance has been largely influenced by individual student factors. In contrast to some of the previous research in the local context, this study confirms the positive contribution of PT on student's academic performance. However, when the coefficients for the PT participation dummy variables across the models were compared, net impact of private tutoring on student's academic performance is found to reduce in magnitude when parental education, economic status and some other social background characteristics are taken into account. Especially, the effect size recorded a significant reduction when the time spent on home work or self-leaning hours per week included.

Second, the results of this study show that higher educational status of the father and also mother plays a crucial role in improving academic performance. This implies that students' family socioeconomic backgrounds clearly affect their academic achievements producing consistent results with some prior studies [31]. Further, the present study examines the influence of parenting behaviors on academic performance mainly through three variables; home supervision, family relationship and cultural capital. The results show that parenting behaviors have a significant positive effect on academic achievement. It was further indicate that parenting behaviors are more important for children's academic achievement is greater than that of PT participation. The findings of this study stressed the importance of parenting behaviors on academic achievement levels. The factors such as fair communication with children about their school life and friends, parental school connectedness through visiting school and participating in school events, supporting and checking homework, understanding children's life in and out of the home, and assuring child safety are all important factors that contribute in improving children's academic achievement. Although the impact is small "perceived teacher quality" improves student's academic performance. This implies that performance is primarily related to a certain trust by students. That is to say, increase in student's traditional trust and respect regarding teachers also contributes to achievement level.

Further, the study established that there is a significant positive relationship between Parental economic status (measured in household expenditure) and Students' Achievement. This result agrees with the previous studies which found out that parents that are rich show more concern over their children's academic achievement. They have the financial ability/potentials to give orientation to their children concerning their educational career right from home. Further, taken together, parental education and high economic status provide the children necessary materials needed including sometimes, individual lesson tutor. This implies that the heterogeneity of educational resource access is a critical factor that has to be concerned by the relevant authorities.

Self studying in the context is mainly created through homework. Homework is any task assigned by teachers for pupils to be carried out during non-instructional time
(Bembenutty 2011 as in [23]) can facilitate practice, preparation and development as an independent learner. Committing on this spillover effects, "Self study hours" has become a strong contributor in explaining student's high academic achievement.

Teacher's effectiveness has been identified as one of the key factors to improve educational outcomes of the learners. This includes teacher quality, teacher competence, time on task, teacher confidence, teacher attitude, teacher qualifications, class size, and teacher personality, teaching load, opportunity to learn and academic orientation etc. Present study found that teacher's experience which increases the subject knowledge, competency, confidence and personality appears to have improved student's performance. Further, implying the difficulties experienced by teachers to manage activities in classrooms with the pressure to complete examination driven syllabi; heavy workloads, overcrowded classrooms, teacher's workload seemed to be governing factor that hinder the student's achievement.

\section{Conclusions}

Private tuition in Sri Lankan context is growing and evolving at an alarming rate. It has been identified as an alternative means of improving students' academic competitiveness. Empirical results of this study show that parents from different socioeconomic backgrounds invest differently in their children's private tutoring and that tutoring is beneficial for children's academic performance [10]. However, the findings strongly suggested that net impact of private tutoring on student's academic performance is reduce in magnitude when parental education, economic status and especially the effect of self-leaning hours is concerned. This clearly implies that PT concentrates only on the requirement for passing the examinations and thereby enfeebles the wider social and cultural goals of education with a narrower focus on examination success. Hence, the findings from this study show that rather than focusing on private tutoring, efforts to improve self-study and self-efficacy which enhance socio-cultural connectedness and human focus can lead to produce a healthy, productive citizen to the economy.

Strong significance of parenting factors concludes that the importance and therefore the need of strengthening student-parent, parent-school relationship in minimizing possible adverse effects of PT and study related stress. This importance of parenting behaviors on predicting children's academic achievement has important policy implications. In particular low-income parents have to work to maintain the household income level. When parents have to work long hours, they might not have enough time and energy to be closely involved with their children while high income parents seek personal tutors to support the children. Therefore, policy strategies that address income issues of low income parents and comprehensive training programs which provide the pathways for effective parent-child communication can improve children's academic achievement. Further, corporative teaching learning with differentiated instruction would be an alternative path to improve student's attitudes towards their teachers and thereby improve their academic performance. Policies 
that incorporate these measure which helps to establish public trust would be helpful in this regard. Moreover, since self-confidence was found to have a significant influence on student's achievements, teachers must their students develop and maintain positive attitudes about their competency level.

Findings of this study imply that self efficacy is an intrinsically valuable component of a child's learner identity in the country as well [23]. Moreover, this study identifies a strong contributory effect of self learning hours operated through homework. Homework has been identified as a social process that has great instructional and communicative purposes. Hence necessary actions are needed to be taken to raise the parental awareness on critical importance of this process. Further, homework planning should be done recognizing the complexity of the social processes involved.

Positive significant relationship appeared between the teacher's teaching experience and performance implied that teachers who have developed greater cognitive abilities tend to generate better learner performance. Therefore, policy actions that provide strong professional development will assist in increasing student's attraction and performance at classroom level. Further, students will be greatly benefitted, if policy actions are taken to reduce lengthy syllabi and heavy workload on teachers

In conclusion, identifying the factors affecting student's academic success is important for all stakeholders in the educational system. The study revealed that parental factors and student self studying as the most influential factors at student level, and teacher quality pays crucial role at classroom level. Even though the present study explains some of the factors that are expected to have practical implications, inherent nature of revealed data on some variables create serious limitations. School sufficiency, likeness, some aspects of teacher quality etc were not sufficient enough to use as predictors. Therefore, further studies should be carried out with different student- and school-level variables to replicate the present study. Moreover, this study focuses only on student's performance measured through marks obtained for certain subjects. Therefore, it is needed to expand the depended variable incorporating multiple aspects of education.

\section{Acknowledgements}

The author gratefully acknowledges the financial support provided by the research council of the University of Sri Jayewardenepura under the Grant number ASP/01/RE/HSS/201/02.

\section{References}

[1] Dang, H. A. (2007). The determinants and impact of private tutoring classes of Vietnam. Economics of education review, 26(6), 684-699.

[2] Tansel, A., \& Bircan, F. (2006). Demand for education in Turkey: a tobit analysis of private tutoring expenditure. Economics of education review, 25(3), 303-313.

[3] Bray, M., \& Kwok, P. (2003). Demand for private supplementary tutoring: conceptul considerations and socio-economic patterns in Hong Kong. Economics of education review, 22(6), 611-620.
[4] Bray, M., \& Kobakhidze, M. N. (2014). The global spread of shadow education. In D. B. Napier, Qualities of education in a globalised world (pp. 185-200). Istanbul: Sense Publishers.

[5] Davies, S. (2004). School choice by default? Understanding the demand for private tutoring in Canada. American Journal of Education, 1-15.

[6] Dang, H.-A., \& Rogers, F. (2008). The growing phenomenon of private tutoring: Does it deepen human capital, widen inequalities, or waste resources? The World Bank Research Observer, 23(2), 161-200.

[7] Bregvadze, T. (2012). Analysing the shadows: private tutoring as a descriptor of the education system of Geogia. International Education Studies, 5(6), 80-89.

[8] Liu, J. (2012). Does cram schooling matter? Who goes to cram school? Evidence from Taiwan. International Jornal of Educational Development, 32(1), 42-56.

[9] De Silva, W.A. (1994b). The present status of private tutoring in Sri Lanka.Economic Review (The People's Bank, Colombo) 20 $(2,3), 4-7,20-24$

[10] Aturupane, H., Glewwe , P., \& Wisniewskiu, S. (2013). The impact of school quality, socio-economic factors and child health on students' academic performance: Evidence from Sri Lankan primary schools. Education Economics, 21(1), 2-37.

[11] Cole, R. (2016). Estimating the impact of private tutoring on academic perofrmance: primary students in Sri Lanka. Education economics, 1-16.

[12] Park, H. and K. Lee. 2005. "Look on Korea Secondary Education through the Analysis of the PISA Study." KEDI Journal of Educational Policy 2(2): 23-38.

[13] Zhang, Y. (2013). Does private tutoring improve students' National College Entrance Exam performance? - a case study from Jinan, China. Economics of education review, 32(1), 1-28.

[14] Thongphat, N. (2012). A survey of Thai student performance in Mathematics and English: Evaluating the effect of supplementary tutoring. Procedia Economics and Finance, 2, 353-362.

[15] Unal, H., Ozkan, E. M., Milton, S., Price, K., \& Curva, F. (2010). The effect of private tutoring on performance in mathematics in Turkey: A comparison across occupational types. Procedia Social and Behavioural Science, 2, 5512-5517.

[16] Byun, S.-y., \& Park, H. (2012). The academic success of East Asian American youth: the role of shadow education. Sociology of education, 85(1), 40-60

[17] Berberoglu, G., \& Tansel, A. (2014). Does private tutoring increase students' academic performance? Evidence from Turkey. Munich Personal RePEc Archive Paper No. 57370.

[18] Kuan, P.-Y. (2011). Effects of cram schooling on mathematics performance: Evidence from junior high students in Taiwan. Comparative Education Review, 55(3), 342-368.

[19] Ha, T. T., \& Harpham, T. (2005). Primar education in Vietnam extra classes and outcomes. International education journal, 6(5), 626-634.

[20] Zhang \& Yu Xie (2016). Family Background, Private Tutoring, and Children's Educational Performance in Contemporary China, Chinese Sociological Review, 48:1, 64-82.

[21] Çikrıkci Ö. (2017). The Effect of Self-efficacy on Student Achievement. In: Karadag E. (eds) The Factors Effecting Student Achievement. Springer, Cham

[22] Williams, Keith, Jennifer Swift, Hefin Williams \& Victor Van Daal (2017). Raising children's self-efficacy through parental involvement in homework, Educational Research.

[23] Chiu, M. M. (2010). Effects of inequality, family and school on Mathematics achievement: Country and student differences. Social Forces, 88(4), 1645-1676.

[24] Heyneman, S. P., \& Loxley, W. A. (1983). The effect of primaryschool quality on academic achievement across twenty-nine highand low-income countries. American Journal of Sociology, 88(6), 1162-1194.

[25] Silva, H. N., \& Banneheka, B. G. (2011). Factors associated with Mathematics results at GCE O/L examination. Vidyodaya Journal of Humanities and Social Sciences, 3, 23-43.

[26] Hanushek, E. A. (1997). Assessing the effects of school resources on student performance: An update. Educational Evaluation and Policy Analysis, 19(2), 141-164.

[27] Dearden, L., Ferri, J., \& Meghir, C. (2002). The effect of school quality on edcational attainment and wages. The review of economics and statistics, 84(1), 1-20. 
[28] Emerson, L., Fear. J., Fox, S., and Sanders, E. (2012). Parental engagement in learning and schooling: Lessons from research. A report by the Australian Research Alliance for Children and Youth (ARACY) for the Family-School and Community Partnerships Bureau: Canberra.

[29] Winter, B. (2013). Linear models and linear mixed effects models in $\mathrm{R}$ with linguistic applications. arXiv: 1308. 5499.

[30] Song, Kyoung-Oh Park, Hyun-Jeong and Sang, Kyong-Ah (2013), A cross-national analysis of the student- and school-level factors affecting the demand for private tutoring, Asia Pacific Educ. Rev. (2013) 14:125-139.

[31] Brehm, W. C., Silova, I., \& Mono, T. (2012). Hidden privatization of public education in Cambodia: the impact and implications of private tutoring. Education support program, 1-44.

[32] Buchmann, C., Condron, D. J., \& Roscigno, V. J. (2010). Shadow education: theory, aAnalysis and future directions: a rejoinder. Social forces, 89(2), 483-490.

[33] De Silva, W.A. (1994a).Extra-school tutoring in the Asian context with special reference to Sri Lanka. Maharagama: Department of Educational Research, National Institute of Education.
[34] Hettige, S. 2004. "From Social Justice to Market Competition Impact of Globalization on Education in Sri Lanka."Presented at the 18th European Conference on Modern South Asian Studies, July 6-9, 2004.

[35] Hong, Song Chang \& Park ,Yoon Soo (2012), An analysis of the relationship between self-study, private tutoring, and self-efficacy on self-regulated learning, KEDI journal of educational policy $\cdot$ 9:1 pp. 113-144.

[36] Park, H., Byun, S.-y., \& Kim, K.-k. (2011). Parental involvement and students' cognitive outcomes in Korea: focussing on private tutoring. Sociology of Education, 84(1), 3-22.

[37] Sunday, Paul Adegoke, Modupe, M. Osokoya., (2015), SocioEconomic Background and Access to Internet as Correlates of Students Achievement in Agricultural Science, International Journal of Evaluation and Research in Education, 4(.1) 16-21.

[38] O'Loughlin, J. (2004). Democratic values in a globalizing world: A multilevel analysis of geographic contexts. GeoJournal 60, 3-17.

[39] Snijders, T. A., \& Bosker, R. J. (2011). Multilevel analysis. An introduction to basic and advanced multilevel modelling. $2^{\text {nd }} \mathrm{Ed}$, London: Sage. 